\title{
Postpartum urinary retention after vaginal delivery: Assessment of risk factors in a case-control study
}

\author{
Sabri Cavkaytar, Mahmut Kuntay Kokanalı, Ayşegül Baylas, Hasan Onur Topçu, Bergen Laleli, Yasemin Taşçı \\ Department of Obstetrics and Gynecology, Dr. Zekai Tahir Burak Woman's Health Education and \\ Research Hospital, Ankara, Turkey
}

\section{Abstract}

Objective: To assess the obstetrics risk factors for postpartum urinary retention after vaginal delivery.

Material and Methods: Of 234 women with a vaginal delivery, 19 (8.1\%) women who had postpartum urinary retention were cases, and 215 (91.9\%) women who did not were controls. Postpartum urinary retention was defined as the presence of postvoid residual bladder volume $\geq 150 \mathrm{~mL}$ or the inability to void within 6 hours after vaginal delivery. Logistic regression analysis identified risk factors for urinary retention.

Results: Prolonged duration of the second stage of labor ( $\mathrm{OR}=0.46,95 \% \mathrm{CI}$ for $\mathrm{OR}=0.06-3.67, \mathrm{p}<0.001)$, presence of episiotomy $(\mathrm{OR}=0.07,95 \%$ $\mathrm{CI}$ for $\mathrm{OR}=0.01-0.68, \mathrm{p}=0.022)$ and perineal laceration $(\mathrm{OR}=97.09,95 \% \mathrm{CI}$ for $\mathrm{OR}=7.93-1188.93, \mathrm{p}<0.001)$, and birth weight of $>4000 \mathrm{~g}$ for the newborn $(\mathrm{OR}=0.04,95 \% \mathrm{CI}$ for $\mathrm{OR}=0.01-0.20, \mathrm{p}<0.001)$ were found as independent risk factors for postpartum urinary retention after vaginal delivery.

Conclusion: Postpartum urinary retention after vaginal delivery is a relatively common condition. Awareness of risk factors, including prolonged second stage of labor, episiotomy, perineal lacerations, and macrosomic birth, may allow us to take the necessary precautions against this complication. (J Turk Ger Gynecol Assoc 2014; 15: 140-3)

Key words: Bladder, delivery, risk factors, urinary retention

Received: 31 May, 2014

Accepted: 14 July, 2014

\section{Introduction}

Postpartum urinary retention (PPUR) is an upsetting condition that has no standard literature definition. It has been variably defined as the abrupt onset of aching or acheless inability to completely micturate, requiring urinary catheterization, over $12 \mathrm{~h}$ after giving birth (1) or not to void spontaneously within 6 h of vaginal delivery (2-4). In 2001, Calgary Health Region's Policy and Procedures outlined acute urinary retention as the catheterization of the bladder within the first $24 \mathrm{~h}$ postpartum for not voiding within $6 \mathrm{~h}$ postpartum, to micturate often in small amounts, or to have an urge to micturate but can not or to be catheterized for any reason for an amount of $500 \mathrm{~mL}$ output within the first $24 \mathrm{~h}$ postpartum (5). One year later, the presence of painful, palpable, or percussible bladder in a patient who is unable to pass any urine was the new definition of acute urinary retention, changed by the International Continence Society (6). Because of this disagreement, and as asymptomatic cases often remain undiagnosed, the exact incidence of PPUR is unknown. However, in the literature, the estimated incidence of PPUR varies between $0.05 \%$ and $37 \%$ (7).

Postpartum urinary retention has been classified into overt and covert retention by Yip et al. (3). Women who are unable to micturate spontaneously within $6 \mathrm{~h}$ after vaginal delivery are categorized as having overt (symptomatic) urinary retention. Covert (asymptomatic) urinary retention is defined as having a postvoid residual bladder volume (PVRBV) of more than $150 \mathrm{~mL}$, detected by ultrasound or by catheterization, with no symptoms of urinary retention.

The precise pathophysiology of PPUr is still unknown; however, it is likely to be multifactorial, including physiological, neurological, and mechanical processes in the postpartum period (7). Inappropriate or delayed diagnosis and management of PPUR can lead to bladder dysfunction, urinary tract infection, and catheter-related complications (8).

Detection of patients who are at risk for developing PPUR might prevent PPUR and its complications. Thus, we aimed to assess the obstetric risk factors that can predict the occurrence of PPUR in women who delivered vaginally.

\section{Material and Methods}

This case-control study was conducted in Dr. Zekai Tahir Burak Woman's Health Education and Research Hospital between January 2014 and April 2014. The study was approved by the institutional review board; 234 consecutive women who delivered term singletons vaginally after uncomplicated pregnancies were included. All participants gave informed consent. 
Immediately after the first micturition in the postpartum period, all of the women underwent a transabdominal ultrasound (Mindray model DC7) to estimate PVRBV. The transducer was located in the midline on the top of the symphysis pubis to obtain the longitudinal and transverse scan of the bladder. The widest diameter in the transverse scan in $\mathrm{cm}$ (D1), the anteroposterior diameter in longitudinal scan in cm (D2), and the cephalocaudal diameter in the longitudinal scan in cm (D3) were recorded. Estimated PVRBV was calculated by using the formula D $1 \times \mathrm{D} 2 \times \mathrm{D} 3 \times 0.7(9)$.

Women in whom the estimated PVRBV $\geq 150 \mathrm{~mL}$ or who were unable to micturate within 6 hours after vaginal delivery were defined as the cases. Women who had an estimated PVRBV $<150 \mathrm{~mL}$ were defined as the controls.

For all participants, maternal and neonatal demographic characteristics (such as age, parity, body mass index (BMI) of the woman, birth weight, head circumference measurement of newborn); gestational age at onset of labor; use of oxytocin and analgesia; duration of the first, second, and third stage of labor; fundal pressure during the second stage of labor; macrosomic delivery (birth weight $>4000 \mathrm{~g}$ ); perineal laceration; episiotomy; and postpartum urinary symptoms (dysuria, frequent urge to urinate without being able to pass much urine, and feeling like bladder not completely empty) were collected.

Statistical analysis was performed using the Statistical Program for Social Sciences (SPSS, Version 15.0; Chicago, IL, USA). The normal distribution of the variables was analyzed by the Kolmogorov-Smirnov test. Continuous variables with normal distribution are presented as mean \pm standard deviation. Median (minimum-maximum) value was used where a normal distribution was absent. Quantitative variables are given as number (percentage). Statistical comparison was carried out by chi-square $(\chi 2)$, Mann-Whitney $U$ - and independent sample t-tests where appropriate. Logistic regression model was performed to analyze risk factors for PPUR. $\mathrm{P}<0.05$ was considered statistically significant.

\section{Results}

Among 234 consecutive women recruited in our study, 19 women had PPUR, with an overall incidence of $8.1 \%$. Of these 19 cases, $18(7.7 \%)$ were covert (asymptomatic) retention, and $1(0.4 \%)$ was overt (symptomatic) retention.

The characteristics of women and newborns are listed in Table 1. There was no significant difference regarding maternal age, gravidity, parity, BMI, gestational period, time between birth to first void, postpartum urinary symptoms of women, and head circumference of newborns between cases and controls. However, the mean birth weight of newborns for cases was statistically significantly heavier than the controls (3745.79 \pm 432.18 grams vs. $3493.63 \pm 492.68$ grams, $\mathrm{p}<0.032$ ). Also, the mean PVRBV of cases was significantly higher than controls (202.11 $\pm 60.15 \mathrm{~mL}$ vs. $57.84 \pm 26.63 \mathrm{~mL}, \mathrm{p}<0.001)$.

With respect to obstetric characteristics, there were no significant differences in duration of the first stage (714. $21 \pm 44.10$ minutes vs. $693.26 \pm 65.20$ minutes, $p=0.171)$ and the third stage of labor (4.74 \pm 0.45 minutes vs. $4.79 \pm 2.83$ minutes, $p=0.934$ )
Table 1. Characteristics of women and newborns

\begin{tabular}{|l|c|c|c|}
\hline & $\begin{array}{c}\text { Cases } \\
(\mathbf{n = 1 9 )}\end{array}$ & $\begin{array}{c}\text { Controls } \\
(\mathbf{n = 2 1 5 )}\end{array}$ & $\mathbf{p}^{*}$ \\
\hline Maternal Age (years) & $27.79 \pm 7.18$ & $26.38 \pm 5.93$ & 0.331 \\
\hline Gravidity & $1(1-3)$ & $2(1-4)$ & 0.475 \\
\hline Parity & $1(0-2)$ & $1(0-3)$ & 0.723 \\
\hline Body Mass Index (kg/m²) & $26.24 \pm 1.47$ & $26.07 \pm 1.57$ & 0.646 \\
\hline Gestational period (days) & $267.74 \pm 8.96$ & $267.56 \pm 7.46$ & 0.924 \\
\hline Birth weight (grams) & $3745.79 \pm 432.18$ & $3493.63 \pm 49268$ & 0.032 \\
\hline $\begin{array}{l}\text { Head circumference } \\
\text { (cm) }\end{array}$ & $50.00 \pm 0.94$ & $49.96 \pm 0.96$ & 0.871 \\
\hline $\begin{array}{l}\text { Time birth to the first } \\
\text { void (hours) }\end{array}$ & $3.93 \pm 1.61$ & $3.11 \pm 1.09$ & 0.042 \\
\hline PVRBV (mL) & $202.11 \pm 60.15$ & $57.84 \pm 26.63$ & $<0.001$ \\
\hline $\begin{array}{l}\text { Postpartum urinary } \\
\text { symptoms }\end{array}$ & $4(21.1)$ & $31(14.4)$ & 0.498 \\
\hline $\begin{array}{l}\text { Data were presented as mean } \pm \text { standard deviation, median (minimum- } \\
\text { maximum and number (\%) } \\
\text { PVRBV: postvoid residual bladder volume } \\
\text { *p<0.05 was considered statistically significant. }\end{array}$ & \\
\hline
\end{tabular}

between cases and controls, respectively. But, the mean duration of the second stage of labor was statistically significantly longer in cases as compared to controls (38.42 \pm 9.44 minutes vs. $23.00 \pm 11.72$ minutes, $\mathrm{p}<0.001)$. Chi-square test showed that cases and controls were similar with regard to incidence of labor induction with intravenous oxytocin $(p=0.811)$ or analgesia use during labor $(p=0.636)$. However, the incidence of fundal pressure during the second stage of labor, macrosomic newborn, episiotomy, and perineal laceration were more common in cases than in controls (Table 2).

When we examined the potential risk factors for PPUR by logistic regression model (Table 3), parity, use of analgesia during labor, duration of the first stage of labor, labor induction with intravenous oxytocin, fundal pressure during the second stage of labor, and time between birth to first void were not significantly related to PPUR. Prolonged duration of the second stage of labor $(\mathrm{W}=16.13$, $\mathrm{OR}=0.46,95 \% \mathrm{CI}$ for $\mathrm{OR}=0.06$ $3.67, \mathrm{p}<0.001$ ), presence of episiotomy $(\mathrm{W}=5.25, \mathrm{OR}=0.07$, $95 \%$ CI for $\mathrm{OR}=0.01-0.68, \mathrm{p}=0.022)$, perineal laceration repair $(\mathrm{W}=12.81, \mathrm{OR}=97.09,95 \% \mathrm{CI}$ for $\mathrm{OR}=7.93-1188.93, \mathrm{p}<0.001)$, and birth weight of $>4000 \mathrm{~g}$ for the newborn $(\mathrm{W}=13.99$, $\mathrm{OR}=0.04,95 \% \mathrm{CI}$ for $\mathrm{OR}=0.01-0.20, \mathrm{p}<0.001$ ) were significant risk factors to predict PPUR after vaginal delivery.

\section{Discussion}

In our study, PPUR after vaginal delivery was found as a relatively common occurrence, with an incidence of $8.1 \%(19 / 234)$. In the literature, the incidence of PPUR varies widely $(10,11)$. But, the estimated incidence is likely to be more, since most cases often remain unforeseen. Overt retention is easily detected, while covert retention is identified only by ultrasound or by catheterization, since most women give no symptoms. 
Table 2. Obstetrics characteristics

\begin{tabular}{|l|c|c|c|}
\hline & $\begin{array}{c}\text { Cases } \\
(\mathbf{n = 1 9 )}\end{array}$ & $\begin{array}{c}\text { Controls } \\
(\mathbf{n = 2 1 5})\end{array}$ & $\mathbf{p}^{*}$ \\
\hline $\begin{array}{l}\text { Duration of the first stage } \\
\text { (min) }\end{array}$ & $714.21 \pm 44.10$ & $693.26 \pm 65.20$ & 0.171 \\
\hline $\begin{array}{l}\text { Duration of the second } \\
\text { stage (min) }\end{array}$ & $38.42 \pm 9.44$ & $23.00 \pm 11.72$ & $<0.001$ \\
\hline $\begin{array}{l}\text { Duration of the third } \\
\text { stage (min) }\end{array}$ & $4.74 \pm 0.45$ & $4.79 \pm 2.83$ & 0.934 \\
\hline $\begin{array}{l}\text { Labor induction with IV } \\
\text { oxytocin }\end{array}$ & $8(42.1)$ & $103(47.9)$ & 0.811 \\
\hline Analgesia during labor & $10(52.6)$ & $99(46.0)$ & 0.636 \\
\hline Fundal pressure & $9(47.4)$ & $44(20.5)$ & 0.018 \\
\hline Macrosomic newborn & $8(42.1)$ & $13(6.0)$ & $<0.001$ \\
\hline Episiotomy & $15(78.9)$ & $102(47.4)$ & 0.015 \\
\hline Perineal laceration & $13(68.4)$ & $49(22.8)$ & $<0.001$ \\
\hline $\begin{array}{l}\text { Data were presented as mean } \pm \text { standard deviation and number (\%). } \\
\text { *p<0.05 was considered statistically significant. }\end{array}$ \\
\hline
\end{tabular}

Table 3. Logistic regression analysis of risk factors for PPUR

\begin{tabular}{|l|c|c|c|c|}
\hline & Wald & p* & OR & $\begin{array}{c}\text { 95\% CI } \\
\text { for OR }\end{array}$ \\
\hline Parity & 0.54 & 0.461 & 0.46 & $0.06-3.67$ \\
\hline Analgesia during labor & 0.77 & 0.381 & 0.97 & $0.89-1.05$ \\
\hline Duration of the first stage & 0.29 & 0.591 & 0.53 & $0.05-5.31$ \\
\hline Duration of the second stage & 16.13 & $<0.001$ & 0.89 & $0.84-0.94$ \\
\hline $\begin{array}{l}\text { Labor induction with IV } \\
\text { oxytocin }\end{array}$ & 0.01 & 0.983 & 0.99 & $0.46-2.14$ \\
\hline Fundal pressure & 0.71 & 0.247 & 0.44 & $0.11-1.78$ \\
\hline Episiotomy & 5.25 & 0.022 & 0.07 & $0.01-0.68$ \\
\hline Perineal laceration & 12.81 & $<0.001$ & 97.09 & $7.93-1188.93$ \\
\hline Macrosomic newborn & 13.99 & $<0.001$ & 0.04 & $0.01-0.20$ \\
\hline $\begin{array}{l}\text { Time from birth to the } \\
\text { first void }\end{array}$ & 1.96 & 0.161 & 8.88 & $0.42-188.19$ \\
\hline OR: odds ratio; Clicon & & & & \\
\hline
\end{tabular}

OR: odds ratio; $\mathrm{CI}$ : confidence interval; PPUR: postpartum urinary retention * $\mathrm{p}<0.05$ was considered statistically significant

In the literature, many different obstetrical risk factors have been considered for the pathogenesis of PPUR; however, the exact etiology of PPUR has not been clearly identified. The incidence of PPUR has been found to be higher in primigravidae than in multigravidae $(10,12)$. In the present study, however, parity was not a risk factor for PPUR. A high incidence of PPUR was reported in patients with regional anesthesia $(12,13)$ and instrument-assisted vaginal delivery (14). But, in our study, there were no women who had regional analgesia or instrumental delivery. In a retrospective analysis of 11,108 vaginal deliveries by Pifarotti et al. (15), PPUR was detected in 105 women, and fundal pressure during the second stage of labor was an important risk factor for the development of PPUR. In our current study, although fundal pressure was statistically more common among the cases than among the controls, it was not found as an effective factor for PPUR in the regression analysis model.

We identified that a prolonged second stage of labor and delivery of macrosomic newborn were the risk factors associated with the occurrence of PPUR. Similarly, Kekre et al. (16) reported that the lengths of the first and second stages of labor were directly related to postpartum urine residual volume, and labor duration $\geq 700$ min was also associated with a greater incidence of PPUR. It is possible that mechanical strength applied to the pelvic muscle floor during prolonged second stage of labor, in addition to the rise in abdominal pressure with a macrosomic baby, may contribute to pelvic and pudendal nerve damage, resulting in neurologic impairment of micturition and, therefore, urinary retention.

We also found that the PPUR incidence was higher in women who had perineal lacerations and episiotomy than in women who had none. Although, episiotomy, birth canal injury, and severe perineal lacerations were reported as being related to increased risk of urinary retention in some studies $(10,17)$, in a recent cross-sectional study, these factors were not found to be effective in developing PPUR (16). However, we think that the pain caused by the repair of episiotomy or lacerations might result in reflex urethral spasm, and PPUR occurs subsequently. Postpartum urinary retention can damage detrusor muscles and parasympathetic nerves of the bladder wall and change detrusor function, as well. Also, increased levels of progesterone during pregnancy and the early puerperium period might cause bladder atony and facilitate detrusor damage $(12,18,19)$. If any delay or misdiagnosis of PPUR occurs, the damage can be irreversible. Thus, early diagnosis and appropriate treatment approaches have great importance. An indwelling catheter can be used for 2 or 3 days if the woman is unable to void; in cases of persistent PVRBV of more than $150 \mathrm{~mL}$, an intermittent clean catheterization is applied until the PVRBV is less than $150 \mathrm{~mL}$ (16).

According to the RCOG Incontinence in Women Study Group, every postdelivery woman should void within 6 hours; if not, catheterization should be performed (20). Also, both the NICE guideline on Postnatal Care and the WHO Technical Consultation on Postpartum and Postnatal Care state that if there is no voiding within 6 hours of birth and the struggle of voiding methods is not successful, the bladder volume should be assessed, and catheterization should be considered (21, 22). Although ultrasonographic measurement of PVRBV in the postpartum patient is doubtful, due to postpartum uterine size (7), several authors $(23,24)$ offer assessment of the bladder accurately by ultrasound, even in the postpartum period. In a recent review including 24 studies, it was concluded that a standard treatment guideline for PPUR is necessary, since there is no sufficient evidence about the catheterization methods for overt PPUR (25). In the same review, it was recommended that both overt and covert PPUR should be regarded as serious conditions. Routine use of bladder scanning by ultrasonography in the early postpartum period may be beneficial. Future studies investigating the cost-effectiveness and advantages of routine postpartum bladder scanning are needed. 
In conclusion, PPUR is a relatively common condition that can cause irreversible damage to bladder function. Longer second stage of labor, delivery of a macrosomic newborn, the presence of perineal lacerations, and episiotomy are significant risk factors for the development of PPUR. Awareness of risk factors may allow the obstetrician to prevent this complication. Further studies with more participants are needed to identify the exact etiology of PPUR and to clarify whether routine postpartum bladder scanning is cost-effective and beneficial.

Ethics Committee Approval: Ethics committee approval was received for this study from the ethics committee of Zekai Tahir Burak Education and Research Hospital.

Informed Consent: Written informed consent was obtained from patients who participated in this study.

Peer-review: Externally peer-reviewed.

Author contributions: Concept - S.C., M.K.K.; Design - S.C., M.K.K.; Supervision - Y.T.; Resource - A.B., H.O.T., B.L.; Materials A.B., B.L.; Data Collection\&/or Processing - A.B., B.L.; Analysis\&/ or Interpretation - S.C., M.K.K., H.O.T.; Literature Search - S.C., M.K.K., H.O.T.; Writing - S.C., M.K.K.; Critical Reviews - Y.T.

Conflict of Interest: No conflict of interest was declared by the authors.

Financial Disclosure: The authors declared that this study has received no financial support.

\section{References}

1. Ramsay IN, Torbet TE. Incidence of abnormal voiding parameter in the immediate postpartum period. Neurourol Urodyn 1993; 12: 179-83. [CrossRef]

2. Andolf E, Fosif CS, Jorgensen C, Rydhstrom H. Insidious urinary retention after vaginal delivery: Prevalence and symptoms at follow-up in a population-based study. Gynecol Obstet Invest 1994; 38: 51-3. [CrossRef]

3. Yip SK, Brieger G, Hin LY, Chung T. Urinary retention in the postpartum period: The relationship between obstetrics factors and the postpartum post-void residual bladder volume. Acta Obstet Gynaecol Scand 1997; 76: 667-72. [CrossRef]

4. Abrams P, Cardozo L, Fall M, Griffiths D, Rosier P, Ulmsten U, et al. Standardization of terminology of lower urinary tract function: Report from the standardization subcommittee of the International Continence Society. Neurourol Urodyn 2002; 21: 167-78. [CrossRef]

5. Calgary Health Region. Bladder care/fluid balance: Intrapartum and postpartum. Women's and Infant Health Policies and Procedures manual. 2001.

6. Abrams P, Cardozo L, Fall M, Griffiths D, Rosier P, Ulmsten U, et al. The standardisation of terminology in lower urinary tract function: report from the standardisation sub-committee of the International Continence Society. Urology 2003; 61: 37-49. [CrossRef]

7. Lim JL. Post-partum voiding dysfunction and urinary retention. Aust N Z J Obstet Gynaecol 2010; 50: 502-5. [CrossRef]
8. Zaki MM, Pandit M, Jackson S. National survey for intrapartum and postpartum bladder care: Assessing the need for guidelines. BJOG 2004; 111: 874-6. [CrossRef]

9. Poston GJ, Joseph AEA, Riddle PT. The accuracy of ultrasound in the measurement of changes in bladder volume. Br J Urol 1983; 55 : 361-3. [CrossRef]

10. Caley ME, Caley JM, Vasdey G, Lesnick TG, Webb MJ, Ramin KD, et al. Factors that are associated with clinically overt postpartum urinary retention after vaginal delivery. Am J Obstet Gynecol 2002; 187: 430-3. [CrossRef]

11. Lee SNS, Lee CP, Tang OSF, Wong WM. Postpartum urinary retention. Int J Urogynaecol Obstet 1999; 66: 287-8. [CrossRef]

12. Liang CC, Chang SD, Chang YL, Chen SH, Chueh HY, Cheng PJ. Postpartum urinary retention after cesarean delivery. Int J Gynecol Obstet 2007; 99: 229-32. [CrossRef]

13. Ching-Chung L, Shuenn-Dhy C, Ling-Hong T, Ching C, Chao-Lun C, Po-Jen C. Postpartum urinary retention: assessment of contributory factors and long term clinical impact. Aust NZ J Obstet Gynecol 2002; 42: 365-8. [CrossRef]

14. Yip SK, Sahota D, Pang MW, Chang A. Postpartum urinary retention. Acta Obstet Gynecol Scand 2004; 83: 881-91. [CrossRef]

15. Pifarotti P, Gargasole C, Folcini C, Gattei U, Nieddu E, Sofi G, et al. Acute post-partum urinary retention: analysis of risk factors, a casecontrol study. Arch Gynecol Obstet 2014; 289: 1249-53. [CrossRef]

16. Kekre AN, Vijayanand S, Dasgupta R, Kekre N. Postpartum urinary retention after vaginal delivery. Int $\mathrm{J}$ Gynaecol Obstet 2011; 112 : 112-5. [CrossRef]

17. Liang CC, Wong SY, Tsay PT, Chang SD, Tseng LH, Wang MF, Soong YK. The effect of epidural analgesia on postpartum urinary retention in women who delivery vaginally. Int J Obstet Anesth 2002; 11 : 164-9. [CrossRef]

18. Groutz A, Hasson J, Gold R, Pauzner D, Lessing J, Gordon D. Persistent postpartum urinary retention: prevalence, obstetrics risk factors and management. J Urol 2008; 179 (4 Suppl): S472. [CrossRef]

19. Jeffery TJ, Thyer B, Tsokos N, Taylor JD. Chronic urinary retention postpartum. Aust N Z J Obstet Gynaecol 1990; 30: 364-6. [CrossRef]

20. MacLean AB, Cardozo L, eds. Incontinence in Women - Study Group Statement. London: Royal College of Obstetricians and Gynaecologists Press; 2002. p. 433-41.

21. Routine Postnatal Care of Women and their Babies. National Institute for Health and Clinical Excellence Guideline 37. London; 2006.

22. World Health Organization. World Health Organization Technical Consultation on Postpartum and Postnatal Care. Geneva: World Health Organization; 2010.

23. Yip SK, Sahota D, Chang A. Determining the reliability of ultrasound measurements and the validity of the formulae for ultrasound estimation of postvoid residual bladder volume in postpartum women. Neurourol Urodyn 2003; 22: 255-60. [CrossRef]

24. Demaria F, Amar N, Biau D, et al. Prospective 3D ultrasonographic evaluation of immediate postpartum urinary retention volume in 100 women who delivered vaginally. Int Urogynecol J Pelvic Floor Dysfunct 2004; 15: 281-5.

25. Mulder FE, Hakvoort RA, Schoffelmeer MA, Limpens J, Van der Post JA, Roovers JP. Postpartum urinary retention: A systematic review of adverse effects and management. Int Urogynecol J 2014 May 20. [Epub ahead of print] 